\title{
Characterisation and social impact of urban youth languages on urban toponymy: S'ncamtho toponomastics in Bulawayo
}

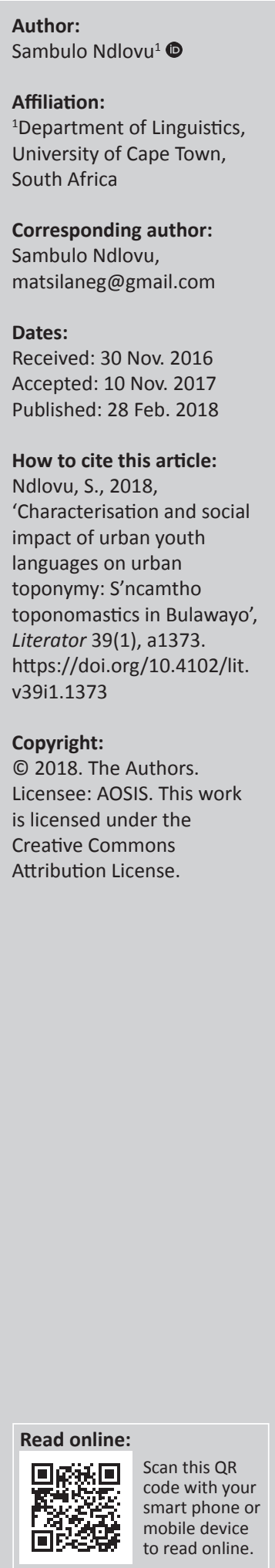

This article focuses on the characterisation of S'ncamtho toponyms in Bulawayo and it goes on to measure the impact of these toponyms on the population of Bulawayo dwellers. S'ncamtho is an urban youth variety that is built on urbanity and streetwise style. The study assumes that, as S'ncamtho is the language of the youth in Bulawayo, people are exposed to S'ncamtho toponyms as the youth are found in all spheres of urban life in Bulawayo, especially the taxi industry which is used by the majority of people in the city. The research collected S'ncamtho verbal toponyms from Godini taxi rank in Bulawayo through undisclosed nonparticipant observations and some from the intuition of the researcher. Intuition and interviews were used to get the etymology of the toponyms and questionnaire tests of familiarity and usage were used to measure the impact of these toponyms on the population. Content analysis is used to characterise and classify S'ncamtho toponyms in Bulawayo and the metaphor comprehension test is used to measure their impact on the population. This article assumes that $S^{\prime}$ ncamtho has its own toponyms for locations in the city and that these are popular, especially with the youth, but people across age groups now use them.

\section{Introduction}

Bulawayo city is the biggest Ndebele urban centre and the hub of S'ncamtho, the Ndebele urban youth variety. Youth style their lives and language - creating their own identity and subculture within a base language and culture. The styling is spread to toponyms and the first target of change and styling is their hometown and in the case of S'ncamtho the hometown is Bulawayo. The youth in Bulawayo have their variety in style and speech and this is also manifested in their naming of environs in the city. The S'ncamtho style overlaps into urban toponymy creating S'ncamtho toponomastics in Bulawayo. Thomas (2001:173) considers place as a relational concept that reflects the ontology and the epistemology of dwellers the world over. The youth and all those who use S'ncamtho in Bulawayo have named some places to reflect their own lifestyle and the character of their language. The hip-hop type culture in S'ncamtho is viewed with suspicion by especially the adult population, and while they may use it, they do not want to consider it formal.

In Bulawayo, the second largest city in Zimbabwe, the popular urban youth variety is christened S'ncamtho, a lingonym borrowed from Zulu-based urban youth varieties in South Africa. While the debate on whether urban youth languages are languages, anti-languages or mere slangs rages on in sociolinguistic research, what cannot be ignored is the fact that these varieties are impacting standard forms of languages, be it positively or negatively. The verbal S'ncamtho toponyms are nicknames of places or stylistic variations of the toponyms while the semiotic ones are signs that passengers, taxi drivers and conductors use to indicate where they are going. This article focuses on the verbalised S'ncamtho toponyms. Toponyms are defined by Moreu-Rey (1965) when he says:

place names or geographic names in their broadest sense, are understood as all the simple and compound names and expressions that designate inhabited places, both today and in the past (the names of countries, of counties, of all kinds of territory, urban and rural agglomerations, -cities, towns, villages and hamlets, as well as subdivisions of these agglomerations ...) as well as uninhabited places. (p. 7)

This research is interested in the names of a city as an agglomeration and its subdivisions. The use of S'ncamtho toponyms in Bulawayo creates the notions of conventional and unconventional toponyms in the city. Tort-Donada (2015:577) notes that: "the "conventional" and the "nonconventional" are, from the point of view of knowledge in general, highly complex categories heavily loaded with ambivalence'. The conventional and unconventional in onomastics is also 
highlighted by Koopman (2002:20) where he identifies conventional and unconventional Zulu anthroponyms as igama lesilungu and igama lasekhaya respectively. Neethling (2003:47) also discusses a similar trend in Xhosa anthroponyms, whereby missionaries gave Euro-origin names to Xhosa children often referred to as 'church' or 'school' names. Hatab (2015:66) notes that Muslim scholars classified names into four classes, which are acceptable names, favoured names, unfavoured names and forbidden names. According to Ndebele purist agendas, S'ncamtho toponyms in Bulawayo fit into the unfavoured names category. Hatab argues that Muslims classify as unfavoured names those which have unacceptable religious, linguistic or social connotations. Despite its widespread use, S'ncamtho is still regarded as having unacceptable linguistic and social connotations.

The study is important as previous literature has shown that youth languages are rapidly spreading in Africa and that they are impacting standard forms (Kioko 2015). There is a gap in critical scholarship that addresses place naming in Africa and other areas outside America and Europe (Azaryahu 2011), and this study contributes to critical scholarship of urban toponymy in Africa. Youth languages in Africa are used in the media, music industry and adverts, and there are claims for some to be used in education such as in Kenya's Sheng (Kioko 2015). This development is worth investigating at an onomastic level, as the youth have been known to name their environment too.

Unconventional naming in urban spaces has been linked to resistance and the need to express dissatisfaction and this has motivated policy changes after regime changes. Azaryahu (2011) addresses urban space renaming in former colonies and notes that the renaming is some form of 'toponymic cleansing' and 'symbolic retribution'. Other scholars have linked renaming to the post-colonial agenda in former colonies (Gill 2005; Swart 2008; Whelan 2003). While S'ncamtho toponyms may be seen by some as ephemeral and passing, studies have actually shown that some elements of slang last long enough to influence language change. Bigon and Njoh (2015) aver that the distinction between conventional and unconventional in African urban toponymy is not clearly determined as the colonisers supplanted toponyms in the colonies replacing them with their own culture, and after independence the colonised undertook name changes creating ambiguities. This study argues that S'ncamtho toponyms are an expression of urban culture and history, and may, in fact, create ambiguities. A similar case is identified by Goodrich and Bombardella (2012) in the South African town of Potchefstroom. Wanjiru and Matsubara (2017) investigated the use of toponyms in Nairobi as a decolonising strategy.

Urban spaces in Africa also consist of informal settlements and spaces that may otherwise not be formally named such as taxi stands or bus stops. It is in this informal urban space that youth and urban language toponyms mostly operate. Wanjiru and Matsubara (2016) argue that slum toponymy in Kenya is a cultural arena for expressing social justice and symbolic resistance. This research is important because it engages urban toponymy that operates informally and measures its impact on the adult population. This indicates an impact on urban Ndebele and the standard forms of Ndebele ultimately.

\section{Methodology}

The research is based on both primary and secondary sources of data and information. It combines both qualitative and quantitative approaches. The methodology of the research is guided by content analysis and idiom testing. S'ncamtho toponyms for Bulawayo locations were collected through nonparticipant observations and intuition. The Godini taxi rank was chosen because it is the central transportation hub to all locations in the city. Taxi crews and passengers use toponyms as part of their major discourse here. The researcher is a native speaker of Ndebele and lives in Bulawayo making intuition a tool for collecting S'ncamtho toponyms. While some of the S'ncamtho toponyms may originate with urban Ndebele, Hurst (2015) has argued that there is little difference between urban youth languages and urban vernaculars. She further states that while urban youth varieties are not slang, they utilise slang generated across the language.

Ditsele and Mann (2014) state that urban youth varieties become an important communication bridge for diverse people in urban centres. In identifying S'ncamtho toponyms, the research made use of Nassenstein's (2016:242) characterisation of urban youth varieties, which include: 'borrowing, calquing, conceptual borrowing, code-switching and other contact phenomena'. There are some toponyms that employ the strategies that are identified with urban youth lexicalisation. The styling techniques which can also be seen, are urban Ndebele. According to McLaughlin (2009), urban youth varieties are growing their domains of use and the community of practice is also increasing. This development takes them closer to urban vernaculars than urban slangs. Mesthrie and Hurst (2013), in their characterisation of tsotsitaal, note that it is a highly stylised slang register of an urban vernacular. S'ncamtho therefore shares a lot with urban Ndebele and toponyms, that are used by the youth, were identified as S'ncamtho, although they can originate from any of the languages and language practices operating within Bulawayo youth.

This research used content analysis as explained by Fraenkel and Wallen (1990) to analyse S'ncamtho toponyms. This was aided by interviews and focus group discussions on the etymology of the toponyms. The Internet and secondary sources of data were also used to trace etymologies. Content analysis was chosen for its advantage of unobtrusiveness as the researcher analysed without being observed.

To measure the social impact of S'ncamtho toponyms in Bulawayo, this research adopted the idiom testing methodology proposed by Nippold and Taylor (2002), which they applied for testing idiom familiarity and usage. They developed a methodology for testing idiom knowledge and 
comprehension. In their study, Nippold and Taylor (2002:386) noted that: 'the participants were asked to perform three tasks in the following order: Familiarity Judgment, Idiom Comprehension, and Transparency Judgment'. The idiom test was chosen because youth varieties are a metaphor for the base language as, Halliday (1976:578) argues that: 'an anti-language is a metaphor for an everyday language; and this metaphorical quality appears all the way up and down the system'. The tests were done on two areas representing low-density and high-density suburbs, which are Burnside and Nkulumane respectively. In each of the two sites, 40 questionnaires were distributed, 10 per group and the groups were male and female youth, and male and female adults. The youth age bracket was set at 20-25 years and the adult age bracket was set at 60-65 years. The ages cohorts were guided by the Zimbabwe youth policy and the retirement age. The age cohort between 25 and 60 consists of people who are too close to the youth variety as they interact with the youth almost daily in the transport industry.

\section{Theoretical framework}

This study is a social practice and socio-historic approach to S'ncamtho toponyms in Bulawayo. It is premised on the social variation and practice theory of sociolinguistics. The study is informed by Bourdieu (1991) and Certeau (1984) who understand language in relation to other social practices. They view language as a social phenomenon, rather than an abstract formal system. Bucholtz (1999) avers that:

the starting point of practice is habitus, the set of dispositions to act (e.g. speak, walk, read, or eat) in particular ways which are inculcated in each individual through implicit and explicit socialisation. These dispositions are linked to particular social dimensions such as class and gender. Habitus is also tied to the body via hexis, the individual's habitual and socially meaningful embodied stances and gestures, and through other aspects of physical self-presentation. Language is merely one practice in which habitus is embodied, and through which the individual becomes socially locatable to observers. (p. 205)

Bourdieu (1991) has also argued that:

not only are linguistic features never clearly separated from the speaker's whole set of social properties (bodily hexis, physiognomy, cosmetics, and clothing), but phonological (or lexical, or any other) features are never clearly separated from other levels of language. (p. 89)

The youth culture is exhibited in their use of language. Onomastics is one field where the youth practice their social identity through language.

The influence of S'ncamtho speakers in Ndebele society yields Ndebele conformity to S'ncamtho, and the social impact theory is used to explain the prevalence of S'ncamtho toponyms in spoken Ndebele. According to Aronson et al. (2007), the social impact theory is a framework that premises social influence on three main pillars, which are a human group's importance, a human group's immediacy and the group's size. They argue that social impact theory predicts that conformity will increase as the strength and immediacy increase. The more important the group is to us, the more likely we are to conform to it. Argo et al. (2005) concur when they note that people are impacted by the real, implied or imagined presence or action of a social presence of a person or group of people. They aver that the impact is from three 'social forces': (1) social size of the group, which is the number of people in the group, (2) immediacy, which has to do with proximity, and (3) social strength of the group, which is the group's importance. S'ncamtho speakers are the urban slick and style trendsetters making them important. Yet, they are always closer to Ndebele speakers and the number has increased over the years. According to the social impact theory, Ndebele cannot be free from heavy S'ncamtho influence at the level of toponymy.

\section{S'ncamtho}

S'ncamtho is a Ndebele-based urban youth variety popular with Bulawayo youth. The debates surrounding the language status of urban youth languages have seen Horne (2010) referring to them as 'slanguages'. Hurst and Mesthrie (2013) have proposed the term stylect after realising that Xhosa tsotsitaal uses Xhosa grammar. Momanyi (2009:131) makes a similar observation on Sheng, the Kenyan youth variety, and notes that it uses Swahili grammar. The fact that the varieties ride on a base language grammar makes it difficult for them to be realised as languages. The name S'ncamtho is derived from the South African youth variety Sqamtho as noted by Bogoda (1999) in his study of youth varieties in Soweto where he noted that the medium of communication among the youth of both sexes in the area is Tsotsitaal, Ringers, Sprake or Sqamtho. Mesthrie and Hurst (2013) also give other types of tsotsitaals in Cape Town such as Gamtaal and Flaaitaal, which are Afrikaans-based tsotsitaals.

S'ncamtho exploits re-lexicalisation to come up with toponyms in Bulawayo. Hurst (2016:155) notes that: 'linguistically, tsotsitaal primarily involves lexical innovation'. She further notes that while there may be differences in South African tsotsitaals, there is some overlap on a national level, which gives tsotsitaal a sort of national identity. S'ncamtho as an Nguni-based tsotsitaal shares in the South African national tsotsitaal overlap. Halliday (1976) categorised youth varieties as anti-languages because of prevalent over-lexicalisation and metaphor. This coupled with high lexical turnover creates the anti-language characteristic in tsotsitaals. However, the urban youth varieties such as S'ncamtho are impacting standard languages positively and at times negatively.

\section{Characterisation of S'ncamtho toponyms in Bulawayo}

Collected S'ncamtho toponyms in Bulawayo were analysed using content analysis and this resulted in the characterisation of the toponyms. In the characterisation, the researcher noted that the toponyms had different characteristics in their derivation and the differences were exploited to come up with categories of S'ncamtho toponyms in the city. The toponyms 
can be classified under two broad characteristics of descriptive S'ncamtho toponyms and structural and stylistic variations. The descriptive S'ncamtho toponyms include those that describe physical features, those that describe socio-economic status and those that describe negative social and physical features. On the structural and stylistic category, there are abbreviations, acronyms, deletions and rhymes.

\section{Physical descriptions as S'ncamtho, toponyms}

It is not surprising to note that Bulawayo has several S'ncamtho names, some of which are trans-generational. The urban landscape has helped produce some S'ncamtho names for Bulawayo town; the high-rise buildings have helped the youth over years to derive descriptive names for the city. Industries and the smoke that they emit into the sky have also helped the youth formulate names for the city, although some of the names are translations and adaptations from English and Afrikaans. 'Colloquially Bulawayo is known by other names: "City of Kings", "Skies", "Bluez", "Bulliesberg" or "KoNtuthuziyathunqa" - a isiNdebele phrase for 'a place that continually exudes smoke'. This name arose from the city's historically large industrial base'. Table 1 gives some S'ncamtho toponyms that describe physical aspects in Bulawayo city and their descriptive etymologies.

The youth have over the years described Bulawayo environs in S'ncamtho and some of these refer to the city while some denote some areas within the city. The influence of urban youth varieties on whole urban populations does not spare urban toponymy, as some of the names for the city are now used by the media, music industry and adults. Names like Blues, Skies, koNtuthu are now as popular as the name Bulawayo itself and can replace it in many instances in the media and music. Hatab (2015:68) argues that, 'what is conventional and unconventional is not static. It is affected by social, political and even environmental factors'. Some of the names that the youth have been giving to areas in the city have stood the test of time and are now being passed from generation to generation.

\section{Class descriptive S'ncamtho toponyms in Bulawayo}

There are some toponyms within the city of Bulawayo that refer to a generic area occupied or historically occupied by

TABLE 1: Physical description of S'ncamtho toponyms in Bulawayo city and their etymologies.

\begin{tabular}{ll}
\hline S'ncamtho toponym for Bulawayo & \multicolumn{1}{c}{ Etymology } \\
\hline eSkies & $\begin{array}{l}\text { Skies - blue smoke 'skies'; the same etymology } \\
\text { has resulted in other descriptive toponyms for } \\
\text { the city such as koNtuthu ziyathunqa and } \\
\text { shortened to koNtuthu, which is a translation } \\
\text { of rising smoke from the industries. The blue } \\
\text { smoke from the industries also derives eBlues. }\end{array}$ \\
koNdonga (at the walls) & $\begin{array}{l}\text { Ndonga ziwelene (high walls) from the high-rise } \\
\text { buildings }\end{array}$ \\
eMdadadeni (at the long houses) & $\begin{array}{l}\text { This is from the physical structures of low-income } \\
\text { flats in Makokoba high-density suburb; they are } \\
\text { conjoined together and long. }\end{array}$ \\
\hline
\end{tabular}

a certain class in society. The city is also colloquially referred to as the city of kings and of late, as city of kings and queens as a result of pressure from gender-equality forums. The historic link between the Ndebele king, Lobengula, and the city is the reason why the youth endearingly use the name. Many youths have lived in the city over the years and each generation has had its own experiences and meaning of the city. S'ncamtho is a black urban variety that is associated with the lower classes in society and, as a result, it at times serves as a language of rebellion. There are some S'ncamtho toponyms within Bulawayo that mark the classes of the namer and named. There are locations that are created along income lines and these have historically divided the city into rich and poor residential areas. As a result of colonial policies this also meant a division between black and white people. There are classes of the rich, middle-class and the poor, which can also be realised as white, mixed race, black middle-class and black poor. Locations where these different classes of people are found have different names in S'ncamtho.

The low-density areas are known in S'ncamtho as emasabhabha [suburbs], emakhiweni or ebalungwini [whitemen's area], emakhitshini [kitchens - because blacks who were found there worked as maids], emayadini [yards], emanozini [at those who speak through their nose - meaning whites] and emasaladini [at the salads - the rich eat salads]. Clarkson (2008) has argued that:

being in the position of the one who chooses names is to be in the position of power; but since names speak of the relation between namer and named, the name of the other is also a way of positioning the self. (p. 135)

There are some middle-class areas that were meant for mixed race people during the colonial era such as Baham Green and Thorngroove. These are called emakhaladini (at the mixed race people). There are some areas within the black suburbs that were reserved for the black middle-class, and these had bigger stands and are colloquially called emastendini (at the stand) and the places include Luveve stands and Luveve 5.

It was noted that the S'ncamtho-speaking youths are from the western high-density suburbs of the city where the majority of poor blacks live. The youth name their locations to mark urbanity and streetwise aptitude and they name areas of the rich as a way of despising and rebellion. Olivier (2014:54) notes that: 'nicknames can perform different functions. Nicknames can serve as identification or classification, but can also serve a social function by indicating relation towards a group identity'. The black suburbs are called emawestern [western areas], ekasi [kas] and elokhshin [location]. While these names denote low in terms of class, the youth put more value in them and mark them as the real urban locations, not the rich areas.

\section{Negative descriptive S'ncamtho toponyms in Bulawayo}

There is another class of S'ncamtho toponyms in Bulawayo that have a class orientation but they carry a negative connotation 
and they are used as phaulisms. Backwardness of certain areas is used to derive S'ncamtho names for the areas. Poverty, underdevelopment and deprivation are used to create names for places in S'ncamtho. Clarkson (2008) avers that:

we use names to refer to something, or to call someone at a place in language, but equally, the names we use give an indication of the place from which we call. That name-place is at a complex intersection of social, cultural, and historical routes. (p. 135)

Historically, the suburbs of Makokoba and Nguboyenja were built for black male workers. The houses are overcrowded and small; the dirt associated with areas has earned them the name eNsikizini [at the bed bugs] in S'ncamtho. Nguboyenja is also called eNgotsheni referring to ingotsha, a hedge used in the poor rural areas; it is also used by the poverty-stricken people in urban areas who cannot afford security walls and fences.

Pumula south is a suburb that was built for blacks far from the city centre. It had no electricity for a long time and people there kept domestic animals, especially donkeys. The place is called emakhaya [rural area] or eMadonkini [at the donkeys]. Bosch (1994:28) asserts that nicknames are not necessarily regarded as permanent as proper names. But historically nicknames in some cases have acquired a more permanent function. The name eMadonkini for Pumula South is now a permanent tag for the area and almost everyone in Bulawayo knows the name. Mganwini is another new high-density suburb in Bulawayo that stayed for a long time without electricity and this earned it the name eMnyameni [dark place].

\section{Stylistic renditions of some Bulawayo toponyms}

The youth employ different styles to derive S'ncamtho names for Bulawayo town and these include using stylising affixes, shortening, using acronyms, abbreviating, shortening and translations. Kießling and Mous (2004:332) agree with Halliday's anti-language classification of youth varieties when they note that the varieties are characterised by linguistic manipulation such as morphological hybridisation, truncation, phonotactic distortions and far-fetched semantic extensions and dysphemisms.

Urban youth varieties are varieties based on style and it is not surprising that some of the S'ncamtho names for the city are stylistic variations and renditions of existing names. Stylistic repetitions, deletions, insertions, translations and abbreviations are all employed in S'ncamtho to derive S'ncamtho toponyms in Bulawayo city. Table 2 gives some of the methods employed to derive stylised S'ncamtho toponyms in Bulawayo.

The stylisation is so robust in some cases that using the toponyms in their stylised versions is akin to rhyming. Many adults know the toponyms, but they would rather not use them. Names such as eS'veveni and eNkust are markers of street identity and urbanity for the youth. Rose (1994:38) quotes the American hip-hop artist Fab Five Freddy as saying:
TABLE 2: Stylised Bulawayo toponyms.

\begin{tabular}{|c|c|c|}
\hline Bulawayo toponym & S'ncamtho rendition & Etymology and styling \\
\hline eluveve & eS'veveni & Styling and rhyming Luveve \\
\hline eNkulumane & eNkust & $\begin{array}{l}\text { Shortening, rhyming and } \\
\text { styling Nkulumane }\end{array}$ \\
\hline eMagwegwe & eWest & Deletion of Magwegwe \\
\hline ePumula north & eNorth & Deletion of Pumula \\
\hline ePumula east & eEast & Deletion of Pumula \\
\hline eOld Lobengula & eOld & Deletion of Lobengula \\
\hline eTown & eToni & $\begin{array}{l}\text { Shortening and styling of } \\
\text { town }\end{array}$ \\
\hline ePumula & eS'phakeni & Styling and rhyming Pumula \\
\hline eBulawayo centre & $\mathrm{eBC}$ & Abbreviation \\
\hline
\end{tabular}

'you make a new style. That is what life on the street is all about. What is at stake is honour and position on the street'. However, the abbreviations such as $\mathrm{eBF}, \mathrm{eBG}$ and $\mathrm{eBC}$ are used across all age groups and they do not carry the 'purist slang stigma'.

\section{Social impact of Bulawayo S'ncamtho toponyms}

Popular culture guides style in youths, especially urban youths, and in America the hip-hop culture has shaped the youth street style and the youth's use of language. Alim (2009) argues that:

youth all around the world have engaged in hip-hop, creating their own versions of hip-hop nation language varieties and communicating to one another through the prism of style to form a global style community. (p. 106)

In the Ndebele context, the local hip-hop culture is the Kwaito and Pansula cultures and these go along with the music genres that are popular with the youth. The youth are so influential in communities today that their languages are impacting the standard forms and names are not spared.

There are some who believe that the youth varieties can be simply shut out and ignored. But Bembe (2006:12) notes that to dismiss slang is tantamount to a failure to recognise its importance and relevance in linguistics and society. Kießling and Mous (2004) are quick to point out that:

urban youth languages start out as linguistic emblems of opposing identities and are perceived first in the frame of 'falling standards' [...], but growing more and more into emblems of a newly emerging project identity. By being adopted by larger portions of the urban population, these sociolects cease to be anti-languages; instead they become established as norms themselves. (p. 334)

Youth varieties the world over are gaining on popularity and use. Table 3 shows the test results on familiarity and usage of five Bulawayo descriptive S'ncamtho toponyms

The descriptive S'ncamtho toponym koNtuthu was popular with both Nkulumane and Burnside respondents scoring a $100 \%$ familiarity and usage across all age groups. The familiarity across all the toponyms indicates that the toponyms have spread across the population. People, including 
TABLE 3: Familiarity and usage of some descriptive Bulawayo S'ncamtho toponyms.

\begin{tabular}{|c|c|c|c|c|c|c|c|c|c|c|c|c|}
\hline \multirow[t]{2}{*}{ Site } & \multirow[t]{2}{*}{ Age group } & \multirow[t]{2}{*}{ Sex } & \multicolumn{2}{|c|}{ koNtuthu } & \multicolumn{2}{|c|}{ Skies } & \multicolumn{2}{|c|}{ eMasaladini } & \multicolumn{2}{|c|}{ eKasi } & \multicolumn{2}{|c|}{ eMadonkini } \\
\hline & & & fam & use & fam & use & fam & use & fam & use & fam & use \\
\hline \multirow[t]{4}{*}{ Nkulumane } & Youth & Male & 10 & 10 & 10 & 10 & 10 & 10 & 10 & 10 & 10 & 10 \\
\hline & & Female & 10 & 10 & 10 & 10 & 10 & 10 & 10 & 10 & 10 & 8 \\
\hline & Adults & Male & 10 & 10 & 10 & 8 & 10 & 9 & 10 & 6 & 10 & 9 \\
\hline & & Female & 10 & 10 & 10 & 10 & 10 & 7 & 10 & 3 & 10 & 2 \\
\hline Subtotal & - & - & 40 & 40 & 40 & 38 & 40 & 36 & 40 & 29 & 40 & 29 \\
\hline \multirow[t]{4}{*}{ Burnside } & Youth & Male & 10 & 10 & 10 & 10 & 10 & 5 & 10 & 4 & 10 & 2 \\
\hline & & Female & 10 & 10 & 10 & 10 & 10 & 6 & 10 & 2 & 8 & 3 \\
\hline & Adults & Male & 10 & 10 & 10 & 10 & 10 & 5 & 10 & 2 & 10 & 0 \\
\hline & & Female & 10 & 10 & 10 & 8 & 8 & 1 & 6 & 0 & 10 & 1 \\
\hline Subtotal & - & - & 40 & 40 & 40 & 38 & 38 & 17 & 36 & 8 & 38 & 6 \\
\hline Grand total & - & - & 80 & 80 & 80 & 76 & 78 & 53 & 76 & 37 & 78 & 35 \\
\hline
\end{tabular}

TABLE 4: Familiarity and usage of some stylised Bulawayo S'ncamtho toponyms.

\begin{tabular}{|c|c|c|c|c|c|c|c|c|c|c|c|c|}
\hline \multirow[t]{2}{*}{ Site } & \multirow[t]{2}{*}{ Age group } & \multirow[t]{2}{*}{ Sex } & \multicolumn{2}{|c|}{ eNkust } & \multicolumn{2}{|c|}{ eToni } & \multicolumn{2}{|c|}{ eEast } & \multicolumn{2}{|c|}{ eBC } & \multicolumn{2}{|c|}{ eSveveni } \\
\hline & & & fam & use & Fam & use & fam & use & fam & use & fam & use \\
\hline \multirow[t]{4}{*}{ Nkulumane } & Youth & Male & 10 & 10 & 10 & 10 & 10 & 10 & 10 & 10 & 10 & 10 \\
\hline & & Female & 10 & 10 & 10 & 8 & 10 & 10 & 10 & 10 & 10 & 7 \\
\hline & Adults & Male & 10 & 7 & 10 & 10 & 10 & 10 & 10 & 10 & 10 & 4 \\
\hline & & Female & 10 & 4 & 10 & 6 & 10 & 10 & 10 & 8 & 8 & 2 \\
\hline Subtotal & - & - & 40 & 31 & 40 & 34 & 40 & 40 & 40 & 38 & 38 & 23 \\
\hline & & Female & 10 & 7 & 10 & 7 & 10 & 10 & 10 & 10 & 9 & 4 \\
\hline & Adults & Male & 10 & 5 & 10 & 10 & 10 & 10 & 10 & 10 & 10 & 3 \\
\hline & & Female & 10 & 3 & 10 & 5 & 10 & 8 & 10 & 10 & 7 & 0 \\
\hline Subtotal & - & - & 40 & 25 & 40 & 29 & 40 & 38 & 40 & 40 & 36 & 14 \\
\hline Grand total & - & - & 80 & 56 & 80 & 63 & 80 & 78 & 80 & 78 & 74 & 37 \\
\hline
\end{tabular}

adults, know the S'ncamtho toponyms and they choose not to use some for reasons of decency. The lowest usage was on eMadonkini, because the respondents felt it is insulting to the people of Old Pumula. The youth have had parallel toponyms to express their understanding of Bulawayo urban spaces. Tort-Donada (2015) avers that:

from the perspective of the philosophy of language, the multiplicity of names is equal to the multiplicity of meanings (that is, the infinite diversity of meaning with which reality presents us). And to reduce this multiplicity to a simple outline, to a list of conventions, is ultimately to reduce the possibilities of language to express the diversity of the world through names. (p. 577)

Descriptive S'ncamtho toponyms are more acceptable to adult Bulawayo dwellers as compared to the stylised ones. Table 4 gives results from familiarity and usage tests on stylised S'ncamtho toponyms in Bulawayo.

There are more $100 \%$ familiarity scores on the stylised toponyms as compared to the scores from descriptive S'ncamtho toponyms. However, the usage scores are lower on the stylised ones on average. The scores indicate that the S'ncamtho toponyms have spread to the whole population. Winkler (2007) argues that:

slang often originates in a particular group and then may spread out to parts of the general population...some slang words even become part and parcel of the common lexicon and may no longer be considered slang. (p. 142)
The toponyms that are shortenings and abbreviations of English names are popular and have spread across the Bulawayo population. Adult and female respondents had reservations in using some of the high-rhyming S'ncamtho toponyms. This is also echoed by Mawadza (2000:93) in her linguistic study of Shona slang in Harare who argued that the variety is viewed with suspicion as a colloquial and vulgar variety. Urban centres are hubs for language contact and it is in such areas that youth varieties thrive. Ditsele and Mann (2014) have looked at the influences of Sepitori, a Tshwane urban variety in South Africa, and note that despite the purist efforts, the variety has an influence on the spoken language of the town.

\section{Conclusion}

Urban centres are conglomerates of different languages and cultures and this gives rise to the urban language phenomena. The data demonstrated that urban youth live in a modern space and they use language practices that are popular with urban youth to create toponyms in Bulawayo. The youth in urban areas create and use language differently in a way that marks the urban style. Urban youth varieties are popular with urban male youth and they tend to spread to the rest of the population-even outside the towns. In Bulawayo, the Ndebele-based youth variety, called S'ncamtho, has influenced urban toponymy in the city as the youth mark the urban centre as theirs through naming it in their variety. The city itself has been named in various S'ncamtho toponyms 
and some of the names are descriptive while some are stylistic. Some of the toponyms used for locations within Bulawayo are class-oriented, while some are descriptive of the people and type of houses. Poverty and backwardness are also used to derive negative toponyms for some locations within the city. Urban style and stylising which include deletions, shortenings, insertions, translations and abbreviations, are employed to derive S'ncamtho toponyms in Bulawayo and some of these are used by people outside the urban male youth bracket. Tests on familiarity and usage of some Bulawayo S'ncamtho toponyms revealed that the toponyms are popular across the population and there is high usage of these S'ncamtho toponyms.

\section{Acknowledgements}

This research was funded by the University of Cape Town.

\section{Competing interests}

The author declares that he has no financial or personal relationship(s) which may have inappropriately influenced him in writing this article.

\section{References}

Alim, H.S., 2009, 'Translocal style communities: Hip hop youth as cultural theorists of style, language, and globalization', Pragmatics 19(1), 103-127. https://doi. org/10.1075/prag.19.1.06ali

Argo, J.J., Dahl, D.W. \& Machanda, R.V., 2005, 'The influence of a mere social presence in a retail context', Journal of Consumer Research 32, 207-212. https://doi. org/10.1086/432230

Aronson, E., Wilson, T.D. \& Akert, R.M., 2007, Social Psychology, 6th rev. edn., Pearson Prentice Hall, Upper Saddle River, NJ.

Azaryahu, M., 2011, 'The critical turn and beyond: The case of commemorative street naming', International E-Journal for Critical Geographies 10(1), 28-33.

Bembe, M.P., 2006, 'The use of slang among black youth in Gauteng', Unpublished MA dissertation, University of Johannesburg.

Bigon, L. \& Njoh, A.J., 2015, 'The toponymic inscription problematic in urban SubSaharan Africa: From colonial to postcolonial times', Journal of Asian and African Studies 50(1), 25-40. https://doi.org/10.1177/0021909613510246

Bogoda, D., 1999, 'African cultural systems and the language in African transition: The case of urban youth in Tsakanetownship in South Africa', African Anthropology vi(2), 259-267.

Bosch, B., 1994, 'Bynnamnavorsing: 'n bestekopname', Nomina Africana 8(2), 27-39.

Bourdieu, P., 1991, Language and symbolic power, Harvard University Press, Cambridge, MA.

Bucholtz, M., 1999, 'Why be normal?: Language and identity practices in a community of Nerd girls', Language in Society 28(2), 203-223. https://doi.org/10.1017/ S0047404599002043

Certeau, M.D., 1984, The practice of everyday life, University of California Press, Berkeley, CA.

Clarkson, C., 2008, 'Remains of the name', in A. de Lange, G. Fincham, J. Hawthorn and J. Lothe (eds), Literary Landscapes: From modernism to post colonialism, pp. 125-142, Palgrave Macmillan, Basingstoke, United Kingdom.

Ditsele, T. \& Mann, C.C., 2014, 'Language contact in African urban settings: The case of Sepitori in Tshwane', South African Journal of African Languages 34(2), 159-165. https://doi.org/10.1080/02572117.2014.997052
Fraenkel, J.R. \& Wallen, N.E., 1990, How to design and evaluate research in education, McGraw-Hill, New York.

Gill, G., 2005, 'Changing symbols: The renovation of Moscow place names', The RussianReview64(3),480-503.https://doi.org/10.1111/j.1467-9434.2005.00371.x

Goodrich, A. \& Bombardella, P., 2012, 'Street name-changes, abjection and private toponymy in Potchefstroom, South Africa', Anthropology Southern Africa 35(1-2) 20-30. https://doi.org/10.1080/23323256.2012.11500020

Halliday, M.A.K., 1976, 'Anti-languages', American Anthropologist 78(3), 570-584. https://doi.org/10.1525/aa.1976.78.3.02a00050

Hatab, W.A., 2015, 'Post colonial anthroponyms in Jordan', in O. Felecan (ed.), Name and naming, proceedings of the third international conference on onomastics. Conventional and unconventional in onomastics, pp. 65-74, Editura Mega, Baia Mare.

Horne, F., 2010, 'Slanguage and AIDS in Africa', Language Matters: Studies in the Languages of Africa 41(1), 25-40. https://doi.org/10.1080/10228191003602036

Hurst, E., 2015, 'Overview of the tsotsitaals of South Africa: Their different base language and common core lexical items', in N. Nassenstein \& A. Hollington (eds.), Youth language practices in Africa and beyond, pp. 169-184, De Gruyter Mouton Inc., Berlin.

Hurst, E., 2016, 'Metaphor in South African tsotsitaal', Sociolinguistic Studies 10(1/2), 153-175.

Hurst, E. \& Mesthrie, R., 2013, “'When you hang out with the guys they keep you in style": The case for considering style in descriptions of South African tsotsitaals', Language Matters 44(1), 3-20. https://doi.org/10.1080/10228195.2012.744082

Kießling, R. \& Mous, M., 2004, 'Urban youth languages in Africa', Anthropological Linguistics 46, 303-341.

Kioko, E., 2015, 'Regional varieties and "ethnic" registers of Sheng', in N. Nassenstein \& A. Hollington (eds.), Youth language practices in Africa and beyond, pp.119-148, Mouton de Gruyter, Berlin.

Koopman, A., 2002, Zulu names, University of Natal Press, Scottsville.

Mawadza, A., 2000, 'Harare Shona slang: A linguistic study', Zambezia xxvii(i), 93-101.

McLaughlin, F., 2009, The languages of urban Africa, Continuum, London.

Mesthrie, R. \& Hurst, E., 2013, 'Slang registers, code-switching and restructured urban varieties in South Africa. An analytic overview of tsotsitaals with special reference to the Cape Town variety', Journal of Pidgin and Creaole Languages 28(1) 103-130. https://doi.org/10.1075/jpcl.28.1.04mes

Momanyi, C., 2009, 'The effects of "Sheng" in the teaching of Kiswahili in Kenyan schools', The Journal of Pan African Studies 2(8), 127-138.

Moreu-Rey, E., 1965, Els noms de lloc. Introduccio a la toponimia, Unio Excursionista de Catalunya, Barcelona.

Nassenstein, N., 2016, 'The new urban youth language Yabacrâne in Goma (DR Congo)', Sociolinguistic Studies 10(1-2), 235-259.

Neethling, J.S., 2003, 'Perceptions around the English names of Xhosa speakers', Nomina Africana 17(2), 45-65.

Nippold, M.A. \& Taylor, C.L., 2002, 'Judgments of idiom familiarity and transparency: A comparison of children and adolescents', Journal of Speech, Language, and Hearing Research, 45(2), 384-391. https://doi.org/10.1044/1092-4388(2002/030)

Olivier, J., 2014, 'Twitter usernames: Exploring the nature of online South African nicknames', Nomina Africana 28(2), 51-74.

Rose, T., 1994, Black noise: Rap music and black culture in contemporary America, Wesleyan University Press, Middletown.

Swart, M., 2008, 'Name changes as symbolic reparation after transition: The examples of Germany and South Africa', German Law Journal 9(2), 105-120.

Thomas, J., 2001, 'Archaeologies of place and landscape', in I. Hodder (ed.), Archaeological theory today, pp. 165-186, Polity Press, Cambridge.

Tort-Donada, J., 2015, "Conventional" and "non-conventional" in microtoponymy, a case study in Catalonia (Spain)', in O. Felecan (ed.), Name and naming, proceedings of the third international conference on onomastics. Conventional and unconventional in onomastics, pp. 577-601, Editura Mega, Baia Mare.

Wanjiru, M. \& Matsubara, K., 2016, 'Slum toponymy in Nairobi: A cultural arena for socio-political justice and symbolic resistance', International Planning History Society Proceedings 17(4), 261-272.

Wanjiru, M.W. \& Matsubara, K., 2017, 'Street toponymy and the decolonisation of the urban landscape in post-colonial Nairobi', Journal of Cultural Geography 34(1) 1-23. https://doi.org/10.1080/08873631.2016.1203518

Whelan, Y., 2003, Reinventing modern Dublin: Streetscape, iconography and the politics of identity, University College Dublin Press, Dublin.

Winkler, E.G., 2007, Understanding language, Continuum, London. 